\title{
HUMPHRY DAVY E AS CORES DOS ANTIGOS
}

\section{Maria Helena Roxo Beltran}

Programa de Estudos Pós-Graduados em História da Ciência, Pontifícia Universidade Católica de São Paulo, Rua Marquês de Paranaguá, 111, 01303-000 São Paulo - SP, Brasil

Recebido em 9/4/07; aceito em 10/8/07; publicado na web em 19/12/07

\begin{abstract}
HUMPHRY DAVY AND THE COLORS OF THE ANCIENTS. This article examines ideas held by Humphry Davy (1778-1829) about permanence, progress, experiments and practical application regarding chemistry. Furthermore, it relates ideas held in his "Some experiments and observations on the colours used in painting by the Ancients" (1815), with those maintained in Elements of Chemical Philosophy (1812), as well as to cogitations from his last years, disclosed in Consolations in travel (1830). Lastly, it brings up evidence that H. Davy's study about the colors of the ancients influenced his proposals for Chemical Philosophy and the science of his age.
\end{abstract}

Keywords: history of chemistry; Humphry Davy; colors of the ancients.

Durante os anos 50, mas especialmente a partir da década de 60 do século XX, métodos físico-químicos de análise, empregando sofisticados instrumentos, passaram a ser cada vez mais utilizados nas pesquisas em arqueologia, bem como em história da $\operatorname{arte}^{1}$. Resultados das pesquisas nesse campo apresentam atualmente especial aplicação no restauro e na conservação de obras de $\operatorname{arte}^{2}$.

Porém, a busca de antigos conhecimentos sobre a matéria, registrados em textos, em objetos e em obras de arte, não é uma preocupação recente. Em relação aos registros deixados por escrito, durante o século XIX, foram realizados grandes levantamentos, traduções e edições de textos originais. No mesmo período, buscando resgatar os segredos dos antigos mestres da pintura, foram realizados, por antiquários e historiadores da arte, levantamentos e traduções de manuscritos concernentes às artes decorativas ${ }^{3}$.

Além disso, já entre os séculos XVIII e XIX, destacados estudiosos procuraram investigar a composição das tintas empregadas pelos antigos nas pinturas murais, inclusive por meio de análise química. Pode-se compreender tal interesse pelas chamadas "cores dos antigos" levando-se em conta a repercussão das notícias sobre as então recentes escavações em Herculano e Pompéia, cidades soterradas havia séculos sob as cinzas do Vesúvio ${ }^{4}$. Além disso, naquela mesma época, experimentos de análise química constituíam objeto de extrema relevância entre os estudiosos. Dessa forma, aqueles recém descobertos registros do passado, guardando vividamente as obras e os materiais conhecidos à época dos romanos, não poderiam escapar ao estudo investigativo que a análise química possibilitaria. Assim, por exemplo, encontram-se entre as publicações do renomado químico J.-A. Chaptal (1756-1832), pelo menos três memórias dedicadas às cores dos antigos ${ }^{5}$.

No início do século XX, as análises de Chaptal sobre as cores dos antigos ainda eram tidas como referência no conhecimento sobre as antigas técnicas de pintura em estudos relacionados à área de conservação e restauro. Tais estudos também destacavam um ensaio escrito por Sir Humphry Davy (1778-1829), considerando que esses

"dois célebres químicos [...] sobre cujas análises se fundamentou toda pesquisa posterior em relação às antigas pinturas de Roma e Pompéia, demonstraram de modo decisivo que as subs-

e-mail: lbeltran@pucsp.br tâncias corantes minerais, vegetais e animais [...] constituem o núcleo principal das cores antigas" ${ }^{\text {. }}$

Porém, mais recentemente, os estudos de Humphry Davy passaram a ser os mais freqüentemente mencionados como referência histórica da área de conservação e restauro ${ }^{7}$. De fato, Davy dedicou-se à análise química das cores dos antigos e publicou seus estudos em 1815, nas Philosophical Transactions of the Royal Society of London, no ensaio intitulado "Some experiments and observations on the colours used in painting by the Ancients"s.

Mas, é intrigante considerar essa preocupação que Davy, tido hoje como um dos ícones da química moderna e de sua aplicação para o progresso da sociedade, dedicava ao passado. Mas, como veremos, a análise da posição desse trabalho sobre as cores dos antigos, no contexto dos estudos químicos realizados por Davy, revela que tal preocupação desse estudioso britânico com o passado dirigia-se, em última análise, ao futuro.

Desde seus tão afamados estudos sobre os gases artificiais, desenvolvidos na Thomas Beddoes's Pneumatic Institution, durante os últimos anos do século XVIII, revelava-se o empenho experimental de Davy nas investigações sobre a composição e a natureza da matéria ${ }^{9}$. Tal empenho seria manifestado em sua plenitude nos estudos envolvendo a eletricidade, os quais retomaria em 1806 e que o levariam ao conhecimento de novos elementos ${ }^{10}$. Isso também o levaria a levantar uma fundamentada discussão das idéias de Lavoisier, ao contestar que o oxigênio fosse o constituinte de todos os ácidos. Para tanto, Davy baseou-se em seus experimentos envolvendo a decomposição do ácido muriático, realizados por volta de $1810^{11}$.

Outro relevante enfoque nos estudos desenvolvidos por Davy relacionava-se a sua preocupação com aplicações práticas dos conhecimentos, como pode ser notado nos estudos sobre química agrícola que desenvolveu entre 1802 e 1812. Além disso, por seu estudo sobre tratamento do couro recebeu, em 1805, a Medalha Copley da Royal Society, sociedade da qual era membro desde 1803. Isso, para não mencionar seu famoso projeto da "lâmpada dos mineiros" (1815). Ainda mais tarde, entre 1823 e 24, por solicitação do Almirantado Britânico, Davy desenvolveria investigações sobre a proteção dos cascos dos navios, cuja aplicação, entretanto, não foi bem sucedi$\mathrm{da}^{12}$. Naquela época, Davy já era presidente da Royal Society, cargo 
para o qual foi eleito, com alguma oposição, em 1820, e que exerceu até 1827 , quando renunciou devido a problemas de saúde ${ }^{13}$.

Esse breve resumo do percurso de Davy já é suficiente para se perceber que, ao publicar o ensaio sobre as cores dos antigos, o estudioso britânico estava no auge de sua carreira. Talvez, Davy tenha sido atraído a realizar tais análises, pela oportunidade que teve de visitar as ruínas em Roma e Pompéia. De fato, em 1813, Davy viajou ao continente para receber medalha do Institut de France, por suas descobertas elétricas. Nessa ocasião, obteve uma permissão especial de Napoleão I para visitar os vulcões na França e na Itália, incluindo, evidentemente, o Vesúvio, em cujas proximidades encontravam-se as escavações de Herculano e Pompéia ${ }^{14}$. Davy retornaria à Inglaterra apenas em 1815 tendo, portanto, tempo suficiente para, entre outros estudos, realizar as análises que descreveu em seu ensaio, as quais detalharemos mais adiante. Além disso, deve-se salientar que Davy levou em sua bagagem aparatos e materiais num laboratório portátil ${ }^{15}$.

Cabe comentar que foi durante essa primeira estada no continente que Davy, testando uma amostra de um material de composição desconhecida que lhe fora presenteada por André-Marie Ampère, identificou um novo "corpo", ao qual deu o nome de iodo. Como é sabido, a identificação desse novo material, sendo também reclamada por Gay-Lussac, configurou-se num dos vários episódios de discussão entre Davy e destacados estudiosos franceses ${ }^{16}$.

Tendo tais discussões em vista, pode-se considerar que, em parte, o interesse de Davy pelo estudo das cores dos antigos tenha sido uma contrapartida britânica às análises feitas anteriormente por Chaptal. De fato, em seu "Some experiments and observations on the colours used in painting by the Ancients", Davy criticou as análises realizadas por aquele renomado estudioso francês. Assim, logo após afirmar em seu texto que "até o momento, acredito, nenhuma tentativa experimental foi feita para identificá-las [as cores dos antigos], ou para imitá-las tais como são peculiares", Davy remete a uma nota na qual se refere particularmente a um estudo publicado por Chaptal nos Annales de Chimie em 1809. Após mencionar sumariamente as cores estudadas pelo químico francês, Davy encerra a nota declarando: "Deverei novamente me referir às observações de $\mathrm{M}$. Chaptal ao longo deste trabalho. Sob leitura cuidadosa, será revelado que elas não superam a investigação mencionada no texto" ${ }^{17}$.

Mas, ao se relacionar este estudo de Davy com outros de seus textos publicados, pode-se construir um quadro em que seu interesse pelas cores dos antigos deixa de parecer um aspecto isolado, ou mesmo mais um episódio envolvendo críticas a investigações realizadas por estudiosos franceses. Isso fica evidenciado na análise da introdução ao seu Elements of Chemical Philosophy e, em especial, nas reflexões registradas em seu trabalho Consolations in travel, escrito nos últimos anos de sua vida. Porém, antes de analisar essas obras, voltaremos nossa atenção ao ensaio "Some experiments and observations on the colours used in painting by the Ancients".

Esse texto estrutura-se nos seguintes itens: introdução, ensaios sobre as cores dos antigos (vermelhos, amarelos, azuis, verdes, pretos e marrons, brancos), considerações "sobre a maneira pela qual os antigos aplicavam suas cores" e, por fim, são apresentadas "algumas observações gerais".

Na introdução a esse ensaio, Davy enfatizou a importância de tal estudo, por meio de um interessante encadeamento de idéias. Em primeiro lugar, destacou o apreço que os antigos gregos tinham pelas obras de arte, bem como o papel que as esculturas, ou o que delas restara, ainda exerciam em seus dias como modelos de perfeição a serem contemplados e seguidos pelos artistas de sua época. Levando isso em conta, admitia que também a pintura, "arte-irmã" da escultura, seria altamente valorizada na antiga Grécia. Entretanto, das pinturas gregas nada restara, o que tornava impossível veri- ficar in loco os materiais e modelos usados pelos mais antigos mestres. Mesmo assim, seria possível fazer uma idéia de tais modelos, observando-se as pinturas em peças de cerâmica e nas paredes das antigas construções romanas, pois a maioria dos mestres romanos seria, conforme Plínio, de origem grega. Além disso, a leitura dos textos clássicos de Teofrasto e sua comparação com obras dos romanos Vitrúvio e Plínio indicavam que os materiais empregados pelos romanos eram os mesmos que haviam sido utilizados pelos mestres gregos. A partir de tais considerações, Davy justificou a análise das pinturas murais romanas, pois elas indicariam tanto os modelos, quanto os materiais que teriam sido utilizados nas certamente superiores pinturas gregas. Mas, ao concluir sua argumentação, Davy foi mais além afirmando que:
"[...] o efeito dos modelos antigos é óbvio; e as várias cópias e imitações que foram feitas desses remanescentes da antigüida- de vem transmitindo seu espírito à arte moderna [...]. Perma- nece, entretanto, um outro uso para o qual [esses remanescen- tes da antigüidade] podem ser aplicados, é aquele de nos tor- nar familiarizados com a natureza e a composição química das cores utilizadas pelos artistas gregos e romanos. As obras de Teofrasto, Dioscórides, Vitrúvio e Plínio contêm descrições das substâncias usadas como pigmentos pelos antigos; mas até agora, acredito, nenhuma tentativa experimental foi feita para identificá-las ou imitá-las em suas peculiaridades" ${ }^{18}$.

Dessa forma, Davy propunha uma nova abordagem para estudar esses "remanescentes da antigüidade", a fim de conhecer a $n a$ tureza e a composição química das cores nelas empregadas. Esse estudo envolveria a realização de testes experimentais com os pigmentos, procurando identificá-los ou mesmo imitá-los. Com isso, Davy acreditava que deveria:
"ser capaz de fornecer informações que não estariam fora do interesse dos homens de ciência e dos artistas, e não [seriam] totalmente desprovidas de aplicações práticas" ${ }^{19}$.

Nos trechos citados, ficam evidenciadas as mesmas preocupações que Davy manifestava em todos os seus estudos: empenho experimental e aplicação prática dos conhecimentos sobre a natureza e a composição da matéria.

Após justificar a importância desse seu estudo, Davy passa a descrever os testes que realizou em suas análises. Mas, antes disso, ainda ao final da "Introdução", o estudioso britânico refere-se às pinturas murais de onde extraiu as amostras, bem como descreve os cuidados que tomou para isso. Conforme relatou, graças à gentileza de seu amigo o famoso escultor Antonio Canova (1757-1822), responsável na época pelas obras de arte antigas de Roma, Davy pôde analisar amostras de diferentes pigmentos encontrados em vasos descobertos nas escavações que então estavam sendo realizadas sob as ruínas do Palácio de Tito ${ }^{20}$. Em seguida, pôde comparar tais pigmentos com amostras extraídas de pinturas murais remanescentes em outros palácios e termas da Roma antiga e de Pompéia, tais como as Termas de Livia, bem como do já então famoso Nozze Aldobrandino ${ }^{21}$. Diante do valor e da raridade de tais obras, Davy dedicava cuidados especiais na extração de amostras para análise. Em suas palavras:

"Quando a preservação de uma obra de arte era levada em
conta, fiz minha pesquisa sobre meros átomos da cor, retirados
de um local onde a perda era imperceptível: e sem danificar
qualquer dos preciosos remanescentes da antigüidade [...]"22

Grande parte do ensaio é dedicada a descrever as diferentes cores e os testes químicos que realizou para determinar os materiais empregados, nos quais, certamente, mais uma vez se utilizou 
do laboratório portátil que levava em sua bagagem.

Assim, dedicando um item específico para cada cor, Davy descreveu os vermelhos em primeiro lugar, a seguir os amarelos, os azuis, os verdes, o púrpura, os negros e marrons e, por fim, os brancos. Além disso, em cada item, comparava suas observações experimentais com as antigas descrições das cores registradas nas obra de Plínio, Vitrúvio e Teofrasto. Entre os testes realizados por Davy, destacam-se aquecimentos com chama direta e em tubo de vidro, observações sobre ação de ácidos e de álcalis e fusão com potassa.

Apesar da declaração de Davy quanto a superar os estudos de Chaptal, nota-se que, de modo geral, os testes descritos e as conclusões apresentadas pelo estudioso britânico não diferem significativamente daqueles registrados anteriormente por seu colega francês. De fato, as críticas de Davy às conclusões de Chaptal concentram-se especificamente nos estudos sobre os azuis dos antigos e à natureza de uma determinada laca rosada.

Vamos aqui focalizar as análises realizadas por Davy e descritas no item IV de seu ensaio, dedicado ao estudo "Das cores azuis dos Antigos" 23 . No decorrer da descrição dos testes realizados, Davy mostra ter analisado amostras extraídas de diferentes câmaras das Termas de Tito e, já de início, pondera que:

"Esses azuis são pálidos ou mais escuros, conforme contenham quantidades maiores ou menores de carbonato de cal, mas quando esse carbonato de cal é dissolvido por ácidos, eles apresentam o mesmo corpo de cor, um pó azul muito fino semelhante ao melhor dos esmaltes ou ao ultramarino, áspero ao toque, e que não perde sua cor quando aquecido ao rubro; mas que se torna aglutinado ou semifundido quando aquecido até embranquecer" ${ }^{24}$.

Em seguida, Davy submeteu esse azul ao ataque de ácidos notando que, embora o sólido resistisse, o:

"Ácido nitromuriático mantido em ebulição durante muito tempo sobre ele [o azul] adquiriu, entretanto, uma suave coloração amarela, e fornecia provas da presença de óxido de cobre."

No teste descrito na sequiência, Davy declara que:

"Uma quantidade da cor foi fundida por uma hora e meia com o dobro de seu peso de hidrato de potassa; a massa que era verde azulada foi tratada com ácido muriático do modo usualmente empregado para análise de pedras silicosas, e ela produziи uта quantidade de sílica equivalente a mais do que 3/5 de seu peso. A matéria corante dissolveu prontamente em solução de amônia, à qual imprimiu um brilhante tom azul, e isso provou ser óxido de cobre. O resíduo produziu uma quantidade considerável de alumina, e uma pequena quantidade de cal"25.

Davy relata ainda ter submetido alguns fragmentos de uma faiança de azul intenso colhidos em uma das câmaras das Termas de Tito a testes químicos, os quais revelaram que tais fragmentos tinham a mesma composição daqueles azuis extraídos dos balneários. Além disso, esses fragmentos de faiança, quando triturados e misturados com giz apresentavam exatamente as mesmas cores das amostras antes analisadas.

Entretanto, ao considerar que quantidades tão pequenas de cal encontradas no azul "não eram suficientes para explicar sua fusibilidade", Davy ponderou que "seria razoável admitir a presença de um álcali fixo". E, assim, para concluir que o azul dos antigos romanos seria mesmo "uma faiança feita com soda e colorida com óxido de cobre", Davy fundiria uma parte desse material com o triplo em peso de "ácido boráxico" e trataria a massa com ácido nítrico e carbonato de amônia. Dessa mistura seria destilado ácido sulfúrico e com todo esse trabalho seria então obtido o sulfato de soda contido no material azul. Seria esse último teste que viria a distinguir de forma mais marcante as análises realizadas por Davy, daquelas anteriormente feitas por Chaptal. De acordo com Davy, que em 1814 teria tido acesso ao azul estudado por Chaptal, "Ele não procurou por álcali, ou haveria toda razão para supor que ele encontraria soda" 26 .

Com esses testes, Davy confirmaria as descrições das cores azuis apresentadas pelos autores clássicos gregos e romanos. Em suas palavras:
"Há toda razão para se acreditar que esta é a cor descrita por Teofrasto como descoberta por um rei egípcio; e cuja manufa- tura é considerada como tendo sido estabelecida em Alexandria. Vitrúvio fala dela, sob o nome de caeruleum, com a cor comumente usada na pintura de câmaras e afirma que em sua época ela era feita em Puzzuoli, para onde o método de fabri- cação foi trazido do Egito por Vestorius; ele dá o método de prepará-la aquecendo-se vigorosamente areia, flos nitri ${ }^{27}, e$ raspas de cobre.
Plínio menciona outros azuis, os quais ele chama de espécies de areia (arenae) das minas de Egito, Scitia e Chipre. Esses azuis naturais, há razão para se crer, eram diferentes preparações de lapis lazuli, e de carbonatos azuis e arseniatos de cobre" ${ }^{\prime 28}$.

Também para Chaptal, os conhecimentos para o preparo desse azul, tão peculiar e distinto, tanto do ultramarino quanto dos outros azuis usados em sua época, seriam de origem egípcia ${ }^{29}$ : "Os procedimentos pelos quais os antigos obtinham essa cor parecem perdidos para nós: tudo o que podemos saber, consultando os anuários das artes, é que o emprego dessa cor remonta a séculos bem anteriores àquele que viu Pompéia desaparecer sob um dilúvio de cinzas: M. Descostils observou uma cor de um azul vivo, brilhante e vitreo sobre as pinturas hieroglíficas de um monumento do Egito, e ele está certo que essa cor é devida ao cobre" ${ }^{30}$.

Ao final desse trecho, Chaptal chegou a comentar que "seria bem interessante investigar os procedimentos de fabricação dessa cor azul", uma vez que ela era muito mais brilhante que os azuis usuais e de preço bem menor que o do ultramarino ${ }^{31}$. Entretanto, ao contrário de Davy, Chaptal não iria mais além.

De fato, na seção final de seu ensaio sobre as cores dos antigos, dedicada a "Algumas observações gerais", Davy declarou ainda ter chegado a reproduzir em laboratório um azul semelhante ao dos antigos, considerando que nele,

"O mais perfeito princípio da composição [...] seria uma espécie de lápis lázuli artificial, a matéria corante naturalmente inerente numa dura pedra de sílica."

E, ainda, no mesmo trecho, Davy relatava:

"Descobri que 15 partes em peso de carbonato de cal, 20 partes de sílex opaco pulverizado e três partes de limalhas de cobre aquecidos energicamente por duas horas fornecem uma substância exatamente do mesmo tom, e aproximadamente do mesmo grau de fusibilidade, a qual, quando pulverizada, produz um belo e profundo azul celeste" 32 .

Dessa forma, Davy mostrava ter realizado seu propósito de analisar e mesmo reproduzir as cores dos antigos. E, sempre atento à durabilidade daquelas cores, encerrando o ensaio, Davy conclui que:

"Os melhores pigmentos são as combinações metálicas insolúveis em água, e que sejam saturadas com oxigênio ou com alguma matéria ácida." 


\section{$[\ldots]$}

"Nos ocres vermelhos o óxido de ferro é totalmente combinado com oxigênio, e nos ocres amarelos ele é combinado com oxigênio e ácido carbônico; e essas cores não se modificaram. Os carbonatos de cobre, que contêm um óxido e um ácido, modificaram-se muito pouco" ${ }_{33}$.

Dessa forma, pode-se perceber que Davy, em seus experimentos sobre as cores dos antigos, procurou identificar e reproduzir aquelas que se mostraram mais duráveis com o tempo, enfatizando, assim, as possíveis aplicações práticas de seu estudo. Nesse mesmo sentido, ao finalizar o ensaio, Davy discorre entusiasticamente sobre as cores "cuja descoberta se deve aos melhoramentos da química moderna", incluindo cores formadas pela nova substância, o iodo ${ }^{34}$.

Assim, o estudioso britânico manifestava, a um só tempo, grande interesse tanto por novas descobertas, quanto pelas descobertas do passado. Tal interesse pelo passado manifesta-se também em outros de seus estudos. De fato, o que Davy pretendia, como pessoa de seu tempo, era contribuir para o progresso do conhecimento e da sociedade, acreditando que para isso seria importante conhecer as realizações do passado.

Em sua época, a química começava a se estabelecer como uma especialidade e Davy ressaltava a definição desse campo de estudo:

"O objeto da Filosofia Química é estabelecer as causas dos fenômenos desse tipo e descobrir as leis pelas quais eles são governados.

Os fins deste ramo de conhecimentos são as aplicações de substâncias naturais a novos usos, para aumentar o conforto e o prazer do homem, e a demonstração da ordem, harmonia e desenho inteligente do sistema da terra.

Os fundamentos da filosofia química são observação, experimento e analogia. Por observação, os fatos são distinta e minuciosamente gravados na mente. Por analogia, fatos semelhantes são relacionados. Por experimento, novos fatos são descobertos; $e$, no avanço do conhecimento, observação, guiada pela analogia, conduz ao experimento, e analogia confirmada por experimento, torna-se verdade científica" ${ }^{35}$.

Esse trecho, com o qual Davy abre a introdução ao seu Elements of Chemical Philosophy, publicado em 1812, apresenta a filosofia química como ramo bem definido do conhecimento, tendo objeto próprio, finalidades específicas e processo de desenvolvimento baseado em princípios claros. Entretanto, mais adiante, Davy pondera que:

"Esses princípios de investigação, e combinação de métodos, têm sido pouco aplicados, a não ser mais recentemente. Um breve olhar ao progresso da filosofia química provará que as descobertas mais brilhantes, e as mais felizes propostas teóricas a ela concernentes têm origem muito recente" ${ }^{" 36}$.

Com essas considerações, Davy justifica que a Introdução ao seu Elements of Chemical Philosophy seja voltada a apresentar alguns "detalhes históricos e observações gerais sobre o progresso e os efeitos [dessa] ciência" ${ }^{37}$. Com isso, percebe-se o empenho de Davy em delimitar o território da química, enquanto conhecimento especializado, bem como em se voltar às realizações do passado que justificariam o progresso e a utilidade desse conhecimento.

Essa mesma atitude de se voltar ao passado visando, entretanto, enfatizar os feitos do presente e as perspectivas de progressos futuros acompanharia Davy por toda a sua trajetória de vida. "A permanência, num mundo de mudanças, era o que [Davy] procurava tanto em sua poesia, e em seus últimos discursos, como no seu trabalho

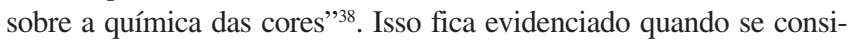
deram seus escritos de final de vida, publicados postumamente em
1830, sob o título Consolations in travel or, The Last Days of a Philosopher $^{39}$. Nessa obra, escrita durante sua última viagem ao continente entre 1826 e 1829, ou seja, após o derrame que o fez afastarse de suas atividades científicas, Davy apresentou reflexões mais gerais sobre o mundo, as sociedades, as ciências e, em particular, a química, ao longo dos seis diálogos em que se estrutura a obra. No primeiro diálogo, intitulado "A Visão", Davy, representado pelo personagem Philalethes, é conduzido pela voz do "Gênio", que lhe aparecera em visão que teve no Coliseu, por uma viagem através dos tempos e do espaço, desde as origens da humanidade, destacando os avanços do homem alcançados por meio do progresso das técnicas. No segundo diálogo, "A Religião", Philalethes conversa com seus amigos sobre a visão que teve, enfatizando a necessidade da fé, além da razão caracteristicamente humana. O terceiro diálogo introduz um novo personagem, o qual, da mesma forma que Philalethes, fala por Davy. Chamado apenas de "O Desconhecido", esse personagem discutirá idéias geológicas. O quarto diálogo, "A Imortalidade", trata de questões fisiológicas e, em especial, da compreensão da vida ${ }^{40}$.

Destacaremos aqui o quinto e o sexto diálogos. O Quinto Diálogo - "Apologia da Química" - inicia-se com um desafio que Philalethes propõe ao Desconhecido, ao afirmar que:

"As altas matemáticas e a física pura me parecem oferecer objetos de contemplação e campos de descoberta mais nobres, $e$, considerados em termos práticos, os resultados da química são muito mais humildes, participando principalmente da botica e da cozinha"41.

Após aceitar o desafio, o Desconhecido inicia sua argumentação, ponderando que:

"As pessoas em geral olham para o magnífico tecido da sociedade civilizada como resultado de trabalho, genialidade e empreendimento do homem acumulados através de um longo curso de eras, sem se preocupar em distinguir o que se deveu aos diferentes ramos da ciência e da indústria humanas; e usualmente atribuem aos políticos, e aos homens de estado e aos guerreiros uma parte da obra muito maior do que a que lhes pertence: o que eles fizeram é realmente pouco. O princípio da civilização é a descoberta de algumas artes úteis pelas quais os homens adquirem propriedade e, conforto e luxo. A necessidade ou desejo de preservá-los levam às leis e às instituições sociais. A descoberta de artes particulares dá superioridade a certas nações; $e$ o amor ao poder induz a empregar essa superioridade para subjugar outras nações, as quais aprendem suas [dos superiores] artes, $e$ por fim adotam suas maneiras; desse modo, a origem, na realidade, bem como o progresso e melhoria da sociedade civil baseia-se nas invenções mecânicas e químicas" ${ }^{2}$.

No decorrer do diálogo, o Desconhecido, sempre confrontando as objeções de Philalethes, vai desenvolver essa idéia, especificando as contribuições das artes do curtume, da fiação e tecelagem, da metalurgia, do vidro e da porcelana ao progresso das sociedades, bem como os princípios da investigação em química, os quais, como vimos, Davy apresentou na introdução ao seu Elements of Chemical Philosophy. Mas, diante dessas considerações do Desconhecido, Philalethes, num dos trechos do diálogo, contra-argumenta afirmando que:

"A maioria das artes úteis, a que chamou químicas, foram inventadas ou aperfeiçoadas sem esse olhar refinado, e sem nenhum sistema geral de conhecimento" ${ }^{43}$.

E o Desconhecido responde:

“[...] Vitrúvio nos informa que o ceruleum, cor composta de cobre, que se mostra em sua perfeição nos velhos quadros dos gregos e romanos, bem como sobre as múmias egípcias, foi des- 
coberto por um rei do Egito. Há portanto todo motivo para crer que isso não foi um resultado de combinações acidentais, mas sim de experimentos para produzir ou aperfeiçoar as cores" ${ }^{4}$.

Assim, deve-se destacar que nesse ponto central à sua argumentação, Davy retoma exatamente aquele azul dos antigos, descrito em seu ensaio "Some experiments and observations on the colours used in painting by the Ancients", de 1815, que tanto lhe interessou por sua beleza e durabilidade.

Também no Sexto Diálogo - O Tempo - Davy retomaria suas conclusões expressas no ensaio de 1815, quando o Desconhecido afirma:

"Na pintura, o lápis lázuli, ou os vidros duros coloridos, nos quais os óxidos não sejam sujeitos a alterações, devem ser usa$\operatorname{dos}[\ldots], 45$.

Isso indica a permanência da preocupação de Davy quanto à destruição e à conservação das obras de arte, pois, como ele afima por meio das palavras do Desconhecido:

"Tempo é quase uma palavra humana e mudança é inteiramente uma idéia humana; no sistema da natureza, deveríamos dizer progresso ao invés de mudança. $O$ sol parece se afundar num oceano de obscuridade, mas ele se eleva sobre um outro hemisfério; as ruínas de uma cidade tombam, mas elas servem muitas vezes para formar construções ainda mais magníficas, como [ocorreu] em Roma" ${ }^{46}$.

Assim, em seu estudo sobre as cores dos antigos, Davy olha para o passado mas se dirige ao futuro. O interesse de Davy pelas "cores dos antigos" ia além de mera curiosidade. Ele passa a se incorporar em suas reflexões sobre o tempo e o progresso.

Conforme as idéias de Humphry Davy, tudo muda, ou melhor, progride. Mas a obra de arte deve resistir ao tempo e às intempéries. As cores e os suportes devem ser os mais duráveis. Entre as cores e os suportes mais duráveis estariam aqueles empregados pelos antigos, os quais resistiram ao tempo. Identificar as cores dos antigos e reproduzí-las era possível graças ao estágio de progresso alcançado pela Química.

\section{AGRADECIMENTO}

Este artigo baseia-se em pesquisa integrante de projetos maiores desenvolvidos junto ao Centro Simão Mathias de Estudos em História da Ciência - PUCSP, apoiado pela FAPESP.

\section{REFERÊNCIAS}

1. Simpósios de Química Arqueológica vêm sendo organizados desde a década de 60 pelo Comitê de Química Arqueológica da American Chemical Society que, atualmente, se liga à Divisão de História da Química dessa Sociedade. Como exemplo das publicações resultantes daqueles primeiros simpósios vide Levey, M. ed.; Archeological chemistry; a symposium, University of Pennsylvania Press: Philadelphia. 1967.

2. Sobre a aplicação de análises físico-químicas na conservação e restauro de obras de arte vide, por exemplo, o número especial da revista Téchne 1995, 2, publicada pelo Laboratoire de Recherche des Musées de France; é interessante notar que esse número comemorou o centenário da descoberta dos Raios X por W. C. Roentgen, cujo emprego na análise de obras de arte vem sendo considerado como marco inicial nesses estudos.

3. Sobre tais estudos vide nosso "O laboratório e o ateliê", em O laboratório, a oficina e o ateliê: a arte de fazer o artificial; Alfonso-Goldfarb, A. M.; Beltran, M. H. R., eds.; Educ/Fapesp/Inep/Comped: São Paulo. 2002, p. 39-60.

4. A descoberta de Herculano data de 1735 e a de Pompéia de 1748; em 1808, iniciou-se a primeira grande escavação em Pompéia.

5. Chaptal, J.-A.; Annales de Chimie 1809, 70, 22-31; Chaptal, J.-A.; Annales de Chimie 1815, 93, 298-313; também há referência a uma notícia sobre as cores encontradas em Pompéia que teria sido publicada em Mémoires de l'Institut 1808, 229-235, conforme Crosland, M. P.; "Chaptal, Jean Antoine", em Gillispie, C. C. ed., Dictionary of scientific biography, Charles Scribner's Sons: Nova York, 1981, vol 3, p. 198-203.

6. Previati, G.; La tecnica della pittura, Fratelli Bocca: Torino, 1923, p. 145154.

7. Vide, por exemplo, Rees-Jones, S. G.; Stud. Conservation 1990, 35, 93-101; também é interessante notar que o ensaio de Davy consta da bibliografia selecionada do site português "Portal de conservação e restauro" http:// www.prorestauro.com, na classe documentação: bibliografia: história das técnicas artísticas, acessado em Março 2007.

8. Davy, H.; Phil. Trans. Roy. Soc. Lond. 1815, 97-124.

9. Sobre o estabelecimento dessa Instituição voltada a investigar o uso medicinal dos gases, vide Levere, T. H.; Notes Rec. Roy. Soc. Lond. 1977, $32,41-49$.

10. Os dados biográficos de Humphry Davy aqui sumarizados baseiam-se especialmente em Knight, D.; "Davy, Humphry", em Gillispie, C. C. ed., op. cit., vol 3, p. 598-604; a trajetória de Davy também é analisada em Ferreira, R.; Quim. Nova 1978, 1, 36-38.

11. Os estudos e as idéias de Lavoisier e, particularmente a nova nomenclatura que propôs, foram criticadas por H. Davy em seu Elements of Chemical Philosophy, J. Johnson: Londres, 1812, p. 42-48, por exemplo; vide também Knight, D.; Ideas in chemistry, Rutgers University Press: New Brunswick, 1992, p. 74-77.

12. James, F. A. J. L.; Physis 1992, 29, 205-225.

13. Miller, D. P.; Brit. J. Hist. Sci. 1983, 16, 1-47.

14. Siegfried, R.; Dott, Jr., R. H.; Brit. J. Hist. Sci. 1976, 9, 219-227.

15. Sobre esses laboratórios portáteis, sua difusão e seus usos entre os séculos XVIII e XIX, vide Homburg, E.; Ambix 1999, 46, 2-5; Knight, D.; Bull. Hist. Chemistry 2004, 29, 3; Knight, D.; Hyle 2006, 12, 131-140.

16. Fullmer, J. Z.; Ambix 1975, 22, 39-51.

17. Davy, H.; Phil. Trans. Roy. Soc. Lond. 1815, 99-100; Davy retomaria e criticaria as observações de Chaptal em notas às páginas 108 e 115 de seu ensaio.

18. Ibid., 99.

19. Ibid., 100

20. Ibid., conforme Knight, D. em "Theory, practice and status, Humphry Davy and Thomas Thomson", em Between the Natural and the Artificial: Dyestuffs and Medicines; Aceves Pastrana, P.; Emptoz, G., eds.; Brepols: Turnhout, 2000, p. 49-58, Davy travou amizade com o escultor Antonio Canova em sua viagem ao continente, e chegou a dedicar-lhe um poema; sobre a obra de Canova e o neoclassissismo, vide Argan, G. C.; Arte moderna, Companhia das Letras: São Paulo, 1992, p. 21-28.

21. Naquela época, esse afresco era propriedade do Signor Nelli, conforme informou Davy ao agradecer a esse senhor a permissão para realizar tais experimentos, cf. Davy, H.; Phil. Trans. Roy. Soc. Lond. 1815, 100; atualmente essa obra faz parte do acervo do Museu Vaticano.

22. Ibid., 100

23. Ibid., 105-109.

24. Ibid., 105-106

25. Ibid., 106

26. Ibid., 107-108, citação em nota.

27. Aqui, Davy introduz a seguinte nota, comentando esse termo: "Isso identifica o nitrum dos antigos com o carbonato de soda"; tal comentário sugere as dificuldades de se poder relacionar certos materiais aos diversos nomes que lhes foram atribuídos desde a Antigüidade; sobre esse tema, em especial no que se refere aos termos "nitrum", "nitro" e "sal nitro", vide nosso "Conhecimentos sobre Compostos de Nitrogênio em De la pirotechnia: discussões sobre a composição elementar do salitre", em: Colóquio CESIMA Ano X/XV Reunião da RIHECQB, 2006, São Paulo. Atas - CESIMA Ano X, Alfonso-Goldfarb, A. M.; Ferraz, M. H. M.; Zaterka, L., eds.; CESIMA/Fapesp/Thomson Gale/Livraria da Física: São Paulo, 2006, p. 290-297.

28. Davy, H.; Phil. Trans. Roy. Soc. Lond. 1815, 107.

29. Esse azul egípcio, também conhecido por faiança, continuaria a atrair a atenção de arqueólogos e químicos. Um levantamento de estudos sobre essa cor realizados até as primeiras décadas do século XX encontra-se em Partington, J. R.; Origins and development of applied chemistry, reimp., Ayer: Salem, 1988, p. 117-119; um exemplo de estudo enfocando análise físico-química de azul egípcio encontra-se em Tite, M. S.; Bimson, M.; Corwell, M. R. em Archaeological Chemistry III; U.S.A., Lambert, J., ed.; American Chemical Society, 1984, p. 215-241; este e outros pigmentos usados pelos egípcios continuam a ser analisados por métodos cada vez mais acurados vide, por exemplo, David, A. R.; Edwards, H. G. M.; Farwell, D. W.; Faria D. L. A. de; Archaeometry 2001, 43, 461-473.

30. Chaptal, J. A.; Annales de Chimie 1809, 70, 25. 
31. Ibid., 26.

32. Davy, H.; Phil. Trans. Roy. Soc. Lond. 1815, 120-121.

33. Ibid., 121.

34. Ibid., 122

35. Davy, H.; Elements of Chemical Philosophy, J. Johnson and Co.: Londres, 1812 , p. $1-2$

36. Ibid., 3 .

37. Ibid.

38. Knight, D.; op. cit.(nota 20), 53.

39. Sobre a relevância atribuída por H. Davy a essa obra, vide Knight, D.; Stud. Romanticism 1967, 6, 66-88.

40. Para comentários sobre cada diálogo, vide Ibid., 66-88; sobre aspectos vitalistas das idéias de H. Davy, vide Knight, D.; Ambix 1976 , 23, 5-15; sobre os personagens como representantes de várias facetas do pensamento de H. Davy, vide Knight, D.; "From science to wisdom: Humphry Davy's life", em Telling lives: essays on scientific biography; Shortland, M.; Yeo, R., eds.; Cambridge, 1996, p. 103-114.

41. Davy, H.; Consolations in travel; or, the last days of a philosopher, Cassel: Londres, 1889, p. 158.

42. Ibid., 158-159.

43. Ibid., 162.

44. Ibid., 163-164.

45. Ibid., 188 .

46. Ibid., 192 